\title{
Prevalence, Causes and Management of Neovascular Glaucoma: A 5-Year Review
}

\author{
B. Fiebai, A. A. Onua* \\ Department of Ophthalmology, University of Port Harcourt Teaching Hospital, Port Harcourt, Nigeria \\ Email: *onuadr@gmail.com
}

How to cite this paper: Fiebai, B. and Onua, A.A. (2019) Prevalence, Causes and Management of Neovascular Glaucoma: A 5-Year Review. Open Journal of Ophthalmology, 9, 1-8.

https://doi.org/10.4236/ojoph.2019.91001

Received: July 4, 2018

Accepted: December 22, 2018

Published: December 25, 2018

Copyright (C) 2019 by authors and Scientific Research Publishing Inc. This work is licensed under the Creative Commons Attribution International License (CC BY 4.0).

http://creativecommons.org/licenses/by/4.0/

cc) (i) Open Access

\begin{abstract}
Purpose: To determine the prevalence, identify the causes and outline the management options available at our center for the treatment of neovascular glaucoma. Setting: The study was carried out in the department of ophthalmology, University of Port Harcourt Teaching Hospital, Port Harcourt, Rivers State, Nigeria. Methods: The case records of all patients who were managed in the department of ophthalmology from January 2013 to December 2017 for neovascular glaucoma were retrieved. Data collected included, age, sex, causes of neovascular glaucoma, presenting visual acuity, treatment options and outcomes, systemic and ocular comorbidities. Results were analysed using Statistical Package for Social Sciences (SPSS) 20.0 for Windows statistical software. Results: Thirty-two eyes (32) of twenty-eight patients were studied. The hospital prevalence of neovascular glaucoma was $0.3 \%$. There were 4 cases of bilateral neovascular glaucoma (NVG). Retinal vein occlusion 17 (53\%) was the commonest cause of NVG followed by proliferative diabetic retinopathy $13(41 \%)$. Uveitis was seen in only $2(6 \%)$ eyes. The commonest form of intervention used was a combination of medical therapy and anti VEGFs. Fifty percent $(50 \%)$ of the study population had a lowering of their intraocular pressures within the normal limits post treatment and this was statistically significant $(\mathrm{p}=0.000)$. However, only $10 \%$ had an improvement in their visual acuity after treatment. Conclusions: Neovascular glaucoma is a potential blinding condition with challenges in control of intraocular pressures and preservation of vision. Early detection and attention to aetiological factors with timely institution of the appropriate mode of treatment may help in preserving vision.
\end{abstract}

\section{Keywords}

Anti-VEGF, Cyclophotocoagulation, Neovascular Glaucoma, Posterior Segment Ischaemia, Rubeosis Iridis, Retinal Vein Occlusion, Proliferative Diabetic Retinopathy 


\section{Introduction}

Neovascular glaucoma (NVG) is a severe form of secondary glaucoma that occurs with blockage of aqueous outflow through the trabecular meshwork due to development of new vessels on the iris (NVI) and iridocorneal angle (NVA) as a result of anterior segment ischaemia. This results in very elevated levels of intraocular pressure (IOP) that eventually culminates in optic atrophy if timely management is not instituted. This usually carries a poor visual prognosis.

NVG was referred to in the past by various names, like rubeotic glaucoma, diabetic haemorrhagic glaucoma, congestive glaucoma, 100 day glaucoma and thrombotic glaucoma [1] [2]. The term neovascular glaucoma was described by Weiss and colleagues in 1963 [3].

The pathogenesis of anterior segment neovascularisation is believed to be a result of a stimulus from the posterior segment ischaemia. Posterior segment ischeamia usually arises from complications of ocular disorders, such as retinal venous and arterial occlusions, proliferative diabetic retinopathy, carotid artery obstructive disease and uveitis [4] [5] [6] [7]. These conditions lead to a hypoxic retina causing ischaemia with release of angiogenic factors which eventually migrate to the anterior segment. Glaucoma then develops through secondary open angle or secondary closed angle mechanisms [8].

Patients usually present with complaints of redness, photophobia and pain of varying intensity, with/or and loss of vision [1].

Ocular examination of these patients most often reveals a profound loss of vision of less than 6/36, elevated intraocular pressures, conjunctival congestion, corneal edema, hyphaema and evidence of posterior segment ischaemia [1].

Further examination of the anterior segment and gonioscopy usually reveals rubeosis iridis and neovascularization of the iridocorneal angle.

In the case of retinal venous occlusion, it takes about 90 days for anterior segment neovascularization to develop, hence the term 90 days glaucoma. This indicates that NVG is a condition caused that arises due to delayed diagnosis and treatment.

Management of neovascularization has evolved in the last decade with the emergence of anti-vascular endothelial growth factors (Anti-VEGFs) [9] [10].

Other modalities of treatment which have been used in the past are still being used in combination with anti-Vegfs, including transscleral cyclophotocoagulation (TSCPC), incisional glaucoma surgery and medical therapy with intraocular pressure lowering drugs.

Successful visual outcome is reduced once NVG is well established. Therefore, timely detection of the risk factors and their control are key players in the prevention of visual loss from this disease as illustrated by this article.

Our study aims to highlight the prevalence and causes of NVG in South-South Nigeria and the treatment modalities available at our centre. There is a dearth of data on neovascular glaucoma in developing countries that enables the comparative analysis of aetiological factors and management outcomes with those else- 
where. This study will add to the body of knowledge in this regard.

\section{Materials and Methods}

Case records of patients attending the retina clinic who were diagnosed with neovascular glaucoma of the University of Port Harcourt Teaching Hospital between January 2015 and December 2017 were reviewed.

Inclusion criteria included all those who had been referred from other clinics to the retina clinic and who had been examined and received treatment in any form for neovascular glaucoma.

The diagnosis of neovascular glaucoma was based on elevated intraocular pressures above $21 \mathrm{mmHg}$ (measured with applanation tonometry) and neovascularization of the iris and/or neovascularization of the angle detected with slit lamp bio-microscopy and gonioscopy.

Parameters evaluated included patients' demographic data, presenting visual acuity, presenting intraocular pressures, ocular and systemic comorbidities, cause of neovascular glaucoma, treatment modalities instituted, final visual acuity and intraocular pressure recorded up to 12 months after treatment. Only patients who had been followed up for up to 12 months were included in this study. Those who did not have proper documentation of their visual acuity or intraocular pressures before or after treatment were excluded from this study.

Twenty-eight patients met the above criteria and were selected for this study.

Information from each subject was entered into a spreadsheet using the Statistical Package for Social Sciences (SPSS) 20.0 for Windows statistical software and analyzed. Comparison of variables was carried out using appropriate statistical tests. P values of $<0.05$ were considered statistically significant.

Ethical clearance was obtained by the relevant institutional board of the hospital.

\section{Discussion}

The hospital prevalence of neovascular glaucoma found in this study was $0.3 \%$. This is slightly higher than that reported in a tertiary hospital in Thailand where a prevalence of $0.012 \%$ was reported. [11] The prevalence in our study was however similar to that reported in population-based studies, which ranged from $0.20 \%-0.55 \%$ [12] [13] [14]. The higher prevalence in our study which is comparable to the population based studies maybe a pointer to a possibly higher prevalence of the risk factors prevalent in our clime which requires more attention, as most are systemic with tendency to causing morbidity and mortality.

The mean age $54.5 \pm 12.97$ years, with an age range between 18 to 76 years (Table 1). This was similar to local and international studies done on NVG. [5] [15] [16]. The similar range of etiological factors such as proliferative diabetic retinopathy, RVO and uveitis reported in these studies could account for this. The highest peaks were seen in the age groups $41-50,51-60$ and $61-70$ years. This is not unexpected as the diseases which are likely to cause NVG are commoner with advancing age. 
Table 1. Age /Gender distribution of the study population.

\begin{tabular}{ccccccc}
\hline \multirow{2}{*}{$\begin{array}{c}\text { Age Group } \\
(\text { Yrs })\end{array}$} & \multicolumn{3}{c}{ Gender } & \multicolumn{3}{c}{$\begin{array}{c}\text { Total } \\
\text { Percentage }\end{array}$} \\
\cline { 2 - 5 } $10-20$ & 0 & 0 & 1 & 3.1 & 1 & 3.1 \\
$21-30$ & 0 & 0 & 1 & 3.1 & 1 & 3.1 \\
$31-40$ & 1 & 3.1 & 1 & 3.1 & 2 & 6.2 \\
$41-50$ & 4 & 12.5 & 3 & 9.4 & 7 & 21.9 \\
$51-60$ & 5 & 15.65 & 5 & 15.65 & 10 & 31.3 \\
$61-70$ & 7 & 21.9 & 3 & 9.4 & 10 & 31.3 \\
70 and Above & 1 & 3.1 & 0 & 0 & 1 & 3.1 \\
TOTAL & 18 & 56.25 & 14 & 43.75 & 32 & 100 \\
\hline
\end{tabular}

Pearson Chi Square $=4.310 ; \mathrm{p}=0.635$. Mean age $=54.5 \pm 12.97$ years. Thirty-two eyes of 28 patients were studied. Age range 18 to 76 years. There was no statistical difference between the ages of the males and females in the study population. Abbreviations: M: Male; F: Female; \%: Percentage.

NVG is a sequalae of vascular and non- vascular disorders of the eye that have the common denominator of retinal ischemia. The commonest cause of NVG in this study was retinal vein occlusion followed by proliferative diabetic retinopathy (Figure 1). The cases of retinal vein occlusion included those with central, hemispheric and branch retinal vein occlusions. Most studies reported a similar trend where retinal venous occlusion and diabetic retinopathy were the two leading causes of NVG [5] [7] [15] [16]. Systemic conditions such as diabetes mellitus and hypertension are the underlying conditions that are implicated in this etiology and this was evident in our study as almost half of our study population 15 (46.9\%) (Figure 1) had a combination of both systemic conditions. Non- vascular disorders appeared to be less common as causative factors. Uveitis 2 (6\%) was a rare causative factor in our study and this was like other studies [16].

NVG is a refractory condition that rarely responds to medical management alone. A combination of several modalities of treatment has been shown to be more effective in intraocular pressure control, although with guarded prognosis than medical management alone [9] [10]. In this study, the most common form of treatment used was a combination of medical therapy with intraocular pressure lowering drugs and anti-vascular endothelial growth factors 13 (40.6\%) (Figure 2). This was due to the fact that the laser therapies were not readily available and patients had to access this outside the facility.

Looking at the intraocular pressure response in the study group overall, there was a statistically significant reduction in IOP $(\mathrm{p}=0.000)$ (Table 3$)$. Only $10 \%$ of the study population however had some improvement in their vision post intervention (Table 2). Fifty-nine percent of our patients had no improvement in their vision (Figure 2) like the China study where 59\% had their visual acuity preserved, buttressing the fact that significant end organ damage occurs as at the 


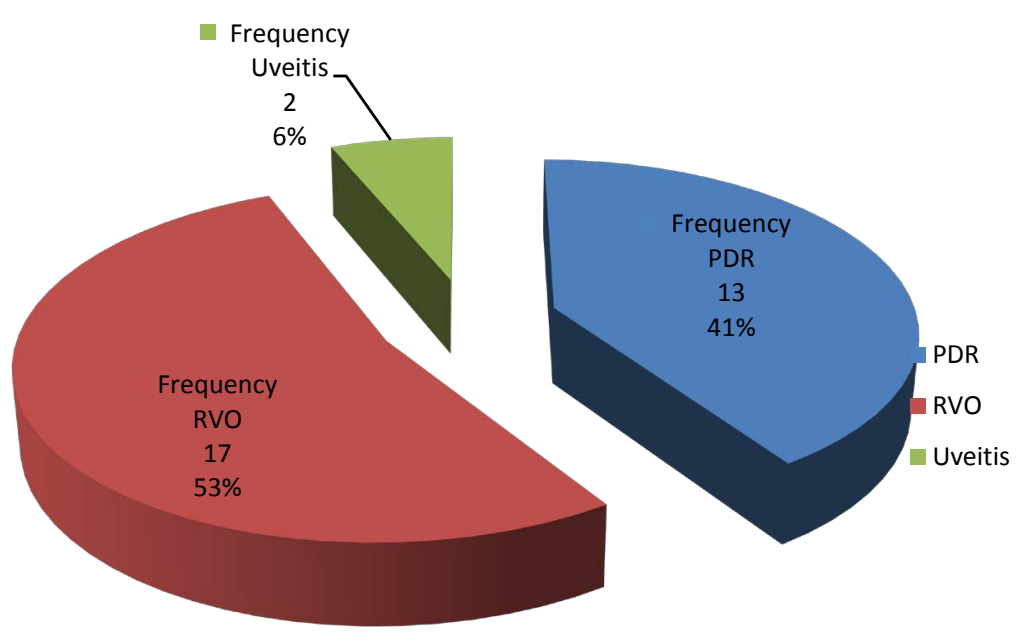

Figure 1. Aetiological Factors of NVG in the Study Population. 17 eyes (53\%) had Retinal vein occlusion, followed by eyes with proliferative diabetic retinopathy $13(41 \%)$ and only $2(6 \%)$ eyes had uveitis. Abbreviations: NVG-Neovascular glaucoma; PDR-Proliferative diabetic retinopathy; RVO-Retinal vein occlusion.

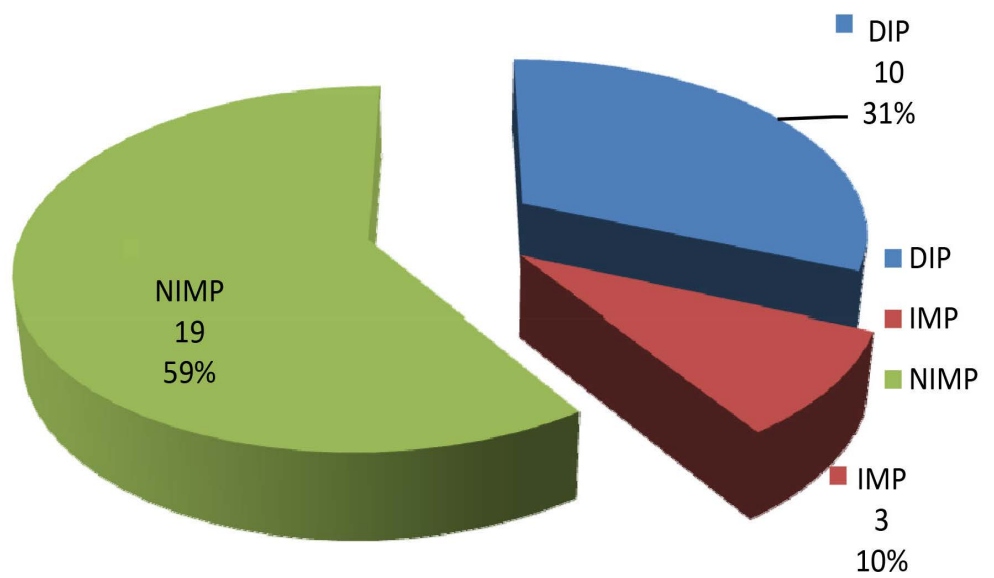

Figure 2. Post intervention outcome in Visual Improvement. Fifty-nine percent of the study population did not have any improvement in visual acuity after treatment. $31 \%$ had a drop in visual acuity while $10 \%$ had some improvement in visual acuity. DIP = DROP IN VISION; IMP = IMPROVED VISION; NIMP = NO IMPROVEMENT IN VISION.

time of presentation in neovascular glaucoma and interventions rarely affect visual outcome positively.

A limitation of this study was its retrospective nature and the small sample size making it difficult to effectively compare the effects of the different modalities of treatment.

\section{Conclusion}

Neovascular glaucoma is a potential blinding condition with challenges in control of intraocular pressures and preservation of vision. The plethora of 
Table 2. Ocular characteristics of eyes with neovascular glaucoma at presentation.

\begin{tabular}{|c|c|c|}
\hline & Number & (Proportion \%) \\
\hline \multicolumn{3}{|l|}{ PRESENTING COMPLAINT(S) } \\
\hline Poor Vision & 18 & $(56.2)$ \\
\hline Pain/Redness & 12 & $(37.5)$ \\
\hline Nil & 2 & $(6.3)$ \\
\hline \multicolumn{3}{|l|}{ ASSOCIATED SYSTEMIC DISEASE } \\
\hline Diabetics Mellitus & 10 & $(31.3)$ \\
\hline Hypertension & 4 & $(12.5)$ \\
\hline Hypertension/Diabetics Mellitus & 15 & $(46.9)$ \\
\hline Nil & 3 & $(9.4)$ \\
\hline \multicolumn{3}{|l|}{ OCULAR CO-MORBIDITY } \\
\hline Cataract & 20 & $(62.5)$ \\
\hline Pseudophakia & 3 & $(9.4)$ \\
\hline Uveitis & 2 & $(6.3)$ \\
\hline Vitreous Haemorrhage & 5 & $(15.6)$ \\
\hline Medical treatment + TSCPC & 2 & $(6.3)$ \\
\hline \multicolumn{3}{|l|}{ EYE AFFECTED } \\
\hline Right Eye & 17 & $(53.1)$ \\
\hline Left Eye & 15 & $(46.9)$ \\
\hline \multicolumn{3}{|l|}{ INTERVENTION } \\
\hline Medical treatment & 12 & $(37.5)$ \\
\hline Medical treatment + Anti-VEGF & 13 & $(40.6)$ \\
\hline Medical treatment + Anti-VEGF + TSCPC & 5 & $(15.6)$ \\
\hline Medical treatment + TSCPC & 2 & $(6.3)$ \\
\hline
\end{tabular}

N/B of the 32 eyes studied, 4 had bilateral disease. Twelve eyes were managed on medical therapy alone which included intraocular pressure lowering medications both topical and systemic. Most eyes, 13 $(40.6 \%)$ received a combination of medical therapy and anti-vascular endothelial growth factors (Bevacizumab). Five eyes had the 3 modalities of treatment, medical, anti-Vegf and transscleral photocoagulation. Only 2 eyes had medical therapy and transscleral cyclophotocoagulation. Abbreviations: Anti-VEGF-Anti-vascular endothelial growth factor; TSCPC—Transcleral cyclophotocoagulation.

Table 3. Clinical outcome of treatment on intraocular pressure (IOP).

\begin{tabular}{ccccc}
\hline $\begin{array}{c}\text { IOP } \\
(\mathrm{mmHg})\end{array}$ & Number & IOP on Presentation & \multicolumn{2}{c}{ IOP Post intervention } \\
\hline $11-22$ & - & 0 & Number & Percentage \\
$23-30$ & 4 & 12.5 & 16 & 50 \\
31 and above & 28 & 87.5 & 7 & 21.9 \\
TOTAL & 32 & 100 & 9 & 28.1 \\
\hline
\end{tabular}

Chi Square $=23.649 ; \mathrm{P}<0.001$. Twenty-eight $(87.5 \%)$ eyes presented with intraocular pressures greater than $31 \mathrm{mmHg}$. After treatment, 16 eyes had intraocular pressures below $22 \mathrm{mmHg}$. The reduction in IOP after intervention was statistically significant. 
treatment options now available can achieve good intraocular pressure control and halt further deterioration of vision. However, early detection and attention to aetiological factors with timely institution of the appropriate mode of treatment is still a key factor in determining visual prognosis.

\section{Conflicts of Interest}

I declare that this article has not been published anywhere previously and is not simultaneously being considered for publication anywhere else.

\section{References}

[1] Shazly, T.A. and Latina, M.A. (2009) Neovascular Glaucoma: Etiology, Diagnosis and Prognosis. Seminars in Ophthalmology, 24, 113-121.

https://doi.org/10.1080/08820530902800801

[2] Rodrigues, G.B., Abe, R.Y., Zangalli, C., et al. (2016) Neovascular Glaucoma: A Review. International Journal of Retina and Vitreous, 2, 26. https://doi.org/10.1186/s40942-016-0051-x

[3] Weiss, D.I., Shaffer, R.N. and Nehrenberg, T.R. (1963) Neovascular Glaucoma Complicating Carotid-Cavernous Sinus Fistula. Archives of Ophthalmology, 69, 304. https://doi.org/10.1001/archopht.1963.00960040310007

[4] Kim, Y.H., Sung, M.S. and Park, S.W. (2017) Clinical Features of Ocular Ischemic Syndrome and Risk Factors for Neovascular Glaucoma. Korean Journal of Ophthalmology, 31, 343-350.

[5] Ashaye, A. and Adeoti, C.O. (2006) Neovascular Glaucoma in a Nigerian African Population. East African Medical Journal, 83, 559-564.

[6] Fiebai, B., Ejimadu, C.S. and Komolafe, R.D. (2014) Incidence and Risk Factors for Retinal Vein Occlusion at the University of Port Harcourt Teaching Hospital, Port Harcourt, Nigeria. Nigerian Journal of Clinical Practice, 17, 462-466. https://doi.org/10.4103/1119-3077.134040

[7] Al-Bahlal, A., Khandekar, R., Al Rubaie, K., Alzahim, T., Edward, D.P. and Kozak, I. (2017) Changing Epidemiology of Neovascular Glaucoma from 2002 to 2012 at King Khaled Eye Specilaist Hospital, Saudi Arabia. Indian Journal of Ophthalmology, 65, 969-973.

[8] Panya, H.K. (2018) Neovascular Glaucoma. http://emedicine.medscape.com/article

[9] Fiebai, B. and Odogu, V. (2017) Intravitreal Anti Vascular Endothelial Growth Factors in the Management of Retinal Diseases: An Audit. The Open Ophthalmology Journal, 11, 315-321.

[10] Sun, Y.Y., Liang, Y., Zhou, P., Wu, H.J., Hou, X.R., Ren, Z.Q., Li, X.X. and Zhao, M.W. (2016) Anti-VEGF Treatment Is the Key Strategy for Neovascular Glaucoma Management in the Short Term. BMC Ophthalmology, 16, 150. https://doi.org/10.1186/s12886-016-0327-9

[11] Kaewkraisorn, C. and Sayawat, N. (2014) Prevalence of Neovascular Glaucoma in Srinagarind Hospital. Srinagarind Medical Journal, 29, 97.

[12] Narayanaswamy, A., Baskaran, M., Zheng, Y., Lavanya, R., Wu, R., Wong, W.L., et al. (2013) The Prevalence and Types of Glaucoma in an Urban Indian Population: The Singapore Indian Eye Study. Investigative Ophthalmology \& Visual Science, 54, 4621-4627. https://doi.org/10.1167/iovs.13-11950 
[13] Landers, J., Henderson, T. and Craig, J. (2012) The Prevalence of Glaucoma in Indigenous Australians within Central Australia: The Central Australian Ocular Health Study. British Journal of Ophthalmology, 96, 162-166.

[14] Ashaye, A., Ashaolu, O., Komolafe, O., Ajayi, B.G., Olawoye, O., Olusanya, B., et al. (2013) Prevalence and Types of Glaucoma among an Indigenous African Population in Southwestern Nigeria. Investigative Ophthalmology \& Visual Science, 54, 7410-7416. https://doi.org/10.1167/iovs.13-12698

[15] Rotimi-Samuel, A., Onakoya, A.O., Musa, K.O., Aribaba, O.T. and Akinsola, F.B. (2014) Neo-Vascular Glaucoma: Etiology and Treatment Outcomes in Lagos. Nigerian Journal of Ophthalmology, 22, 16-19. https://doi.org/10.4103/0189-9171.142749

[16] Liao, N., Li, C., Jiang, H., Fang, A., Zhou, S. and Wang, Q. (2016) Neovascular Glaucoma: A Retrospective Review from a Tertiary Center in China. BMC Ophthalmology, 16, 14. https://doi.org/10.1186/s12886-016-0190-8 